\title{
From the Editor of Sexuality and Disability: Hot Topics in the Field of Sexuality
}

\author{
Sigmund Hough
}

Published online: 25 October 2012

(C) Springer Science+Business Media New York 2012

\section{Hot Topics in the Field of Sexuality}

In 2012, we again found ourselves with a wealth of hot topics in the field of sexuality. Original papers, medial reviews, commentaries, book reviews and topic reviews provided a steady stream of intellectual thought and design for pragmatic application. Still, much remains to be said, discuss, and do.

In the December 2012 issue, hot topics include a review of human and moral rights in relation to the legal system in Ireland for adults with intellectual disabilities; a look at specialists' attitudes towards sexuality of people with intellectual and physical disabilities in Poland; impact of sexuality transmitted infections in South Korea; as well as three articles from Turkey looking at nursing students' attitudes about patients living with HIV/ AIDS, emergency nurses' barriers to intervention of domestic violence, and the effect of difficulties experienced by parents of 12 children with Autism on their sexual life.

Sexuality and Disability provides original impact articles addressing the mental health and medical aspects of sexuality in relation to rehabilitation, hospital, academic and community settings, publishing up-to-date articles, case studies, clinical practice reports, reviews, featured articles, historical articles, special grand rounds topics, brief research reports and survey data reports. Value benefit is provided to authors through worldwide electronic exposure and professional access, while readership gains from scholarly contributions to advance the field through research, best-practice and educational articles. The refined lens of individual contributions from the local and international community continues to deliver a wealth of information on the topic of sexuality and disability for the reader. Thank you for joining us.

S. Hough $(\bowtie)$

396 Washington Street, Suite 211, Wellesley Hills, MA 02481, USA

e-mail: Sigmund_Hough@hms.harvard.edu 